\title{
Research on the Evaluation of Green Development of Logistics Industry in East China under the "Carbon Peak and Carbon Neutrality" Goal
}

\author{
Baojie Fu \\ School of Management Science and Engineering, Anhui University of Technology, Ma'anshan, \\ China
}

1937411404@qq.com

\begin{abstract}
The strategy decision of "Carbon Peak and Carbon Neutrality" has brought extensive and complex impact to China's economic and social development. In order to achieve the "Carbon Peak and Carbon Neutrality" goal, it is significant to promote the green development of the logistics industry, a high energy-consuming industry. Combined with the industry norms and relevant policy documents of logistics industry, this study selected secondary indicators containing four aspects of finance, resource, operation and environment, and eight tertiary indicators, and constructed the evaluation indicator system of green development of logistics industry in East China. Quantitative analysis and qualitative analysis of the green development of logistics industry in East China from 2015 to 2019 were conducted using entropy weighting TOPSIS method, and comprehensive performance and ranking of six provinces and one city were obtained. Results showed that Shandong Province ranked the highest in terms of the green development of logistics industry; Jiangsu Province and Zhejiang Province took the second and third places respectively, and Shanghai came in last. Finally, based on the in-depth analysis of empirical results, this paper provided suggestions for the green development of the logistics industry in East China.
\end{abstract}

Keywords: Carbon Emission Peaking; Carbon Neutrality; Green Development of Logistics Industry; Entropy Weighting TOPSIS Method.

\section{Introduction}

With the growth of social urbanization, economic development and energy consumption, China's carbon emissions have continued to rise in the past two decades, and the national total carbon emissions reached 9,899 million tons in 2020, ranking first in the world. In addition, among the world's major countries, China's share of world carbon emissions is still growing and has increased to $31 \%$ in 2020 . As the world's largest developing country, China is in a critical period of urbanization and industrialization, facing the dual serious challenge of coordinating economic growth and reducing carbon emissions. The report of the 19th National Congress emphasized the concept of green and low-carbon development of the national economy, proposed the dual carbon targets of carbon emission peaking and carbon neutrality, and issued a series of policy documents.

It can be seen that the industrial model of sacrificing the environment for economic benefits has been eliminated by the times, and many national economic sectors such as industry, transportation and electric power should implement industrial green upgrading in accordance with their actual situation so as to help achieve the double carbon goal. As an emerging service industry as well as an energy-intensive industry, logistics industry plays an important part in the national economy. According to the data of the National Bureau of Statistics, in 2017, the total energy consumption of China's logistics industry was second only to the manufacturing industry, amounting to 421.91 million tons of standard coal, accounting for $9.4 \%$ of the total national energy consumption in that year. Therefore, the green development of the logistics industry should be an inevitable trend. From the perspective of regional economy, modern logistics industry, with a wide and strong influence and competitiveness, is an indispensable subsystem of a perfect regional economic system, which plays an extremely important role in adjusting and improving the industrial structure, promoting and strengthening regional economic development. In addition, from the perspective of industrial structure, modern logistics industry is a comprehensive service industry integrating various industries 
including circulation, processing, transportation, storage, information interaction, etc. Therefore, it acts as an important part of China's national economy and plays a significant role in promoting production, employment and consumption, which not only advances its own stable development, but also supports the development of other industries.

East China is one of the regions with the fastest economic growth in China. In order to implement the economic development strategy of East China, it is of great significance to optimize regional industrial division and industrial layout, clarify the positioning of industrial development in six provinces and one city, and accelerate industrial transformation and upgrading. At present, domestic research on logistics industry mainly focus on overall evaluation, with little attention on hierarchical analysis and local analysis, especially the analysis of the green development of the whole logistics industry. In terms of research methods, most scholars are more inclined to unilateral qualitative or quantitative analysis, which can be biased to some extent. Therefore, this paper selects East China as the research area, and adopts a combination of quantitative and qualitative analysis based on adequate relevant data of the green development of logistics industry in East China, so as to objectively and comprehensively evaluate its current situation and reasons behind, and timely find out problems and make suggestions.

\section{Literature Review}

At present, research on regional logistics at home and abroad mainly focus on industrial structure, economic development and influencing factors, primarily based on qualitative analysis and effect evaluation. The basic idea is to start from qualitative analysis, construct a reasonable evaluation indicator system, and use various methods to analyze and process the data indicators and make a comprehensive evaluation, so as to obtain evaluation results and policy implication. For example, $\mathrm{Li}$ and Lyu (2022) analyzed the carbon emission characteristics of Beijing-Tianjin-Hebei since 1997 based on the two dimensions of carbon emission scale and carbon emission intensity, explored the interrelationship between industrial structure and carbon emission of Beijing-Tianjin-Hebei, and concluded that optimizing the industrial structure of Beijing-Tianjin-Hebei, adjusting energy consumption structure, promoting energy-saving and emission reduction technology innovation, especially optimizing the industrial structure of Hebei Province, and promoting the development of advanced manufacturing industries in Hebei Province, would help achieve the "carbon peak and carbon neutrality" goal.[1] By constructing the evaluation index system of logistics development, Shi and Li (2021) established five primary evaluation indexes and nine secondary evaluation indexes based on the survey of economic development level, logistics infrastructure, logistics human resources, logistics innovation capacity and logistics development potential to evaluate the highquality development of logistics in Henan Province and find out the most influential factors.[2] Li and Zhang (2018) used DEA method to analyze and evaluate the efficiency of logistics industry in East China and obtained the conclusion that logistics efficiency can be improved by introducing highly qualified talents and advanced technology, and adjusting the input and output structure. [3] Mei et al. (2019) used the SEA model to exclude relevant influencing factors and calculated accurate regional logistics industry efficiency based on three-stage DEA model.[4] Wang (2021) used factor analysis to analyze some key factors significantly influencing regional logistics efficiency, and obtained results through empirical research that the 21 indicators in the original evaluation index system could be reduced to 8 comprehensive indicators including regional economic development level, regional logistics scale, logistics cost, etc.[5] Wang and Wang (2015) examined the relationship between carbon emissions and economic benefits of the logistics industry in Henan Province using the energy consumption reduction method, and concluded that vigorously developing "low-carbon logistics" and strengthening environmental constraints can promote the "inflexion point" of carbon emissions to appear in advance.[6] Yang and Zhang (2021) constructed an index system to evaluate the effect of green transformation in the logistics industry, and used factor analysis to evaluate the effect of green transformation in the logistics industry in 30 provinces (municipalities and 
autonomous regions) in China, and explored the common characteristics of logistics industry development in various provinces using cluster analysis method.[7] Xie et al. (2019) used multiple linear regression method for empirical analysis and selected five comprehensive indicators in four major aspects of operation management, environmental construction, economic development and infrastructure construction through hierarchical analysis, profoundly analyzed the reasons affecting the ranking of logistics green performance in East China, and put forward their own suggestions.[8] $\mathrm{Su}$ and Chen (2021) took 42 listed companies in heavy pollution manufacturing industry as an example to build an ESG evaluation system containing 3 sub-goals, 11 guideline level indicators and 43 specific indicators, to establish indicator weights using AHP-entropy combination weigh method, and to establish an evaluation model using TOPSIS method.[9] Zhou (2016) used principal component analysis to screen 11 indicators from the three aspects of total logistics scale, logistics supply capacity and logistics demand, thus constructing a comprehensive index to measure the development level of logistics industry in East China.[10]

Foreign studies such as Soleimani et al. (2021) applied the Augmented Weighted Chebyshev (AWT) method and the e-constraint method to address the multi-objectivity of the problem, while the robust optimization method was used to deal with the uncertainty of demand, which provided effective solutions for designing a green closed-loop supply chain network.[11] Choudhary et al. (2020) used a combined approach of Best-Worst Method (BWM) and Decision-Making Trial and Evaluation Laboratory (DEMATEL) to identify "Total Quality Management" and "Cleaner Production Technology" as the most important causal dimensions of environmentally sustainable supply chain management.[12] Ramanathan et al. (2020) used case study observations from three global companies to develop a conceptual model and conducted a questionnaire survey to test the conceptual model, and the results indicated that the environmental positioning (green objectives) of the companies would enhance their business and financial performances.[13] Rehman et al. (2019) explored the relationship between green logistics indicators and economic, environmental and social factors from the perspective of emerging Asian economies, using a fully modified OLS (FMOLS) model and a dynamic OLS (DOLS) model approach to test the research hypotheses, taking the issues of endogeneity and serial correlation into consideration, and the results showed that logistics operations, especially LPI2 (customs clearance process efficiency), LPI4 (logistics service quality) and LPI5 (trade and transport related infrastructure) are significantly and positively correlated with per capita income, manufacturing value added and trade openness.[14] Hooker et al. (2019) explored the relationship between green supply chain management (GSCM) and green innovation practices and the impact of these practices on environmental performance in 123 manufacturing firms that obtained ISO 14001 certification, and the results showed a significant positive relationship between GSCM and green innovation and environmental performance.[15] Khan et al. (2019) used two methods, GMM (Generalized Method of Moments) and FGLS (Feasible Generalized Least Squares), to address the problems of heterogeneity, serial correlation and heteroskedasticity. Their research explored the relationship between green logistics operations and social, environmental and economic indicators in South Asian Association for Regional Cooperation (SAARC) countries, and concluded that the application of green energy resources and green practices can mitigate the negative effects on social and environmental sustainability due to better logistics operations while improving financial performance in terms of increased global GDP per capita, trade openness, and export opportunities. [16] Laari et al. (2021) based on a national logistics survey in Finland and financial reports of 266 logistics firms data, examined their competitive strategies and green supply chain management (GSCM) and tested their respective relationships with environmental and financial performance.[17] Bag et al. (2021) explored the relationships between institutional pressures, eco-innovation, green supply chain management (GSCM) practices, CE capability, big data driven supply chains (BDSC), and CE supply chain performance through the lens of institutional and dynamic capability view theories. [18] Stekelorum et al. (2021) examined the extent to which different combinations of internal and external green supply chain management (GSCM) practices affect third-party logistics providers (TPLs) based on the natural resource-based view and coordination theory, and a fuzzy 
qualitative comparative analysis of survey data from 232 TPLs showed that combination of internal and external GSCM practices improved operational and financial performance. [19] AgyabengMensah et al. (2021) explored the impact of GLMPS, logistics eco-centricity and supply chain traceability on sustainability performance through a structured questionnaire survey, and the results showed that logistics eco-centricity and supply chain traceability enhanced GLMPS and further significantly improved firm performance and environmental sustainability, playing a mediating role.[20]

In summary, existing comprehensive evaluation studies on the green development of regional logistics basically focused on economic indicators in terms of indicator selection, failing to take industrial development and energy use into account. Considering various economic indicators and green development indicators at the same time would be more conducive to a comprehensive evaluation of the development performance of logistics industry. In addition, most of the analyses on regional logistics were carried out from the aspects of concept, development status and countermeasure suggestions, and the research methods were mostly based on qualitative analysis and effect evaluation. In terms of the selection of research area, there have been fewer studies on logistics industry in East China; in terms of research direction, there have been fewer studies focusing on green development of logistics industry, and even fewer studies combining the two. Therefore, this paper adopts the entropy TOPSIS method, combining qualitative and quantitative analysis, to carry out the research on the green development of logistics industry in East China.

\section{Model and Method}

It is one the key issues to determine the weight of indicators to establish the evaluation system of the green development of logistics industry in East China. The subjective weighting method and the objective weighting method are the two commonly used methods to determine the evaluation indexes. The subjective assignment method refers to the determination of weights based on subjective consciousness, which is simple and easy to implement but arbitrary and prone to large deviations, with the representing methods such as AHP hierarchical analysis and Delphi method. On the contrary, the objective weighting method does not depend on human consciousness, but has the basis of targeted mathematical theory, and can obtain more objective weights, with the representing methods such as the entropy method, coefficient of variation method, mean square deviation method, etc. Considering that the evaluation of green development of logistics industry in East China involves various factors, it is more suitable to use the combination evaluation method to rank and evaluate such comprehensive indicators, so this paper adopts the entropy weighting TOPSIS method.

The entropy weight method is an objective weighting method that determines the position of an indicator among all indicators by using the amount of information contained within the indicator. TOPSIS method, a commonly used intra-group comprehensive evaluation method, can make full use of the original data information.

The combined application of entropy weighting method and TOPSIS method has many unique advantages in terms of the evaluation of industry development. Firstly, the application of objective weighting effectively overcomes the subjective interference of human factors and provides higher accuracy and reliability. Secondly, there are no strict regulations and restrictions on the distribution range of data, the number of observations and indicators, which makes this method highly applicable and easy to calculate. Thirdly, the evaluation criteria are the positive and negative ideal solutions calculated by the TOPSIS method, which is an innovative approach to the selection of evaluation criteria. Fourth, the evaluation results of TOPSIS method are more hierarchical and can make full use of the raw data provided to evaluate the single-level and multi-level, horizontal and vertical situations of the object, which has the advantages of both local and overall evaluation.

According to the entropy weighting TOPSIS method, the specific steps to establish the evaluation model of green development of logistics industry in East China are as follows. 
(1) Based on the data information of evaluation objects, an initial decision matrix $A$ including $m$ evaluation objects and $n$ evaluation indicators is established.

There are $m$ indicators to evaluate the advantages and disadvantages of $n$ solutions, and $x_{i j}$ refers to the value of $j$ indicator of $i$ solution, so that the initial decision matrix $\left(x_{i j}\right)_{m \times n}$ can be constructed

$$
A=\left(x_{i j}\right)_{m \times n}=\left[\begin{array}{cccc}
x_{11} & x_{12} & \cdots & x_{1 n} \\
x_{21} & x_{22} & \cdots & x_{2 n} \\
\cdots & \cdots & \cdots & \cdots \\
x_{m 1} & x_{m 2} & \cdots & x_{m n}
\end{array}\right]
$$

(2) Normalize $A$ to obtain the normalized norm matrix $B$.

$$
B=\left(b_{i j}\right)_{m \times n}=\frac{x_{i j}}{\sum_{j=1}^{n} x_{i j}},(i=1,2, \cdots, m),(j=1,2, \cdots, n)
$$

(3) Calculate the information entropy value of indicators by the entropy weighting method. Let the entropy of the $j$ indicator

$$
e_{j}=-k \sum_{i=1}^{m} b_{i j} \ln b_{i j}
$$

In order to make $0 \leq e_{j} \leq 1$, we take $k=\frac{1}{\ln m}>0$, where $b_{i j}$ is the value of the $j$ indicator of $i$ evaluation object after standardization.

(4) Calculate the difference coefficient $v_{j}$ based on the above information entropy value $e_{j}$. For a given $j$, the smaller the degree of difference of indicator $p_{i j}$, the larger the entropy value $e_{j}$ and the smaller the difference coefficient $v_{j}$, and the smaller the weight of $j$ indicator, and vice versa. The calculation formula is

$$
v_{j}=1-e_{j}
$$

(5) Calculate the entropy weight. We normalize $v_{j}$ and obtain the weight of each indicator $w_{j}$. Then we have

$$
w_{j}=\frac{v_{j}}{\sum_{j=1}^{n} v_{j}}=\frac{1-e_{j}}{n-\sum_{j=1}^{n} e_{j}}, j=1,2, \cdots, n
$$

where $0 \leq w_{j} \leq 1, \sum_{j=1}^{n} w_{j}=1$.

(6) The entropy weights derived from the previous step are multiplied with the normalized matrix $B$ to obtain the weighted normalization matrix $T$.

$$
T=\left[\begin{array}{cccc}
b_{11} w_{1} & b_{12} w_{2} & \cdots & b_{1 n} w_{n} \\
b_{21} w_{1} & b_{22} w_{2} & \cdots & b_{2 n} w_{n} \\
\cdots & \cdots & \cdots & \cdots \\
b_{m 1} w_{1} & b_{m 2} w_{2} & \cdots & b_{m n} w_{n}
\end{array}\right]=\left[\begin{array}{cccc}
r_{11} & r_{12} & \cdots & r_{1 n} \\
r_{21} & r_{22} & \cdots & r_{2 n} \\
\cdots & \cdots & \cdots & \cdots \\
r_{m 1} & r_{m 2} & \cdots & r_{m n}
\end{array}\right]
$$

(7) Determine the positive ideal solution, i.e., the optimal solution $O_{j}^{+}$and the negative ideal solution, i.e., the inferior solution $O_{j}^{-}$, then we have

$$
\begin{aligned}
O_{j}^{+} & =\left\{\left[\max \left(r_{1 j}, r_{2 j}, \cdots, r_{n j}\right) \mid j \in S^{+}\right],\left[\min \left(r_{1 j}, r_{2 j}, \cdots, r_{n j}\right) \mid j \in S^{-}\right]\right\} \\
O_{j}^{-} & =\left\{\left[\min \left(r_{1 j}, r_{2 j}, \cdots, r_{n j}\right) \mid j \in S^{+}\right],\left[\max \left(r_{1 j}, r_{2 j}, \cdots, r_{n j}\right) \mid j \in S^{-}\right]\right\}
\end{aligned}
$$


where $S^{+}$refers to benefit-based indicators, $S^{-}$refers to cost-based indicators.

(8) Calculate the Euclidean spatial distance of each evaluation object to the positive ideal solution $D_{i}^{+}$and the Euclidean spatial distance to the negative ideal solution $D_{i}^{-}$. The specific calculation formula is

$$
\begin{gathered}
D_{i}^{+}=\sqrt{\sum_{j=1}^{n}\left(r_{i j}-H_{j}^{+}\right)^{2}},(j=1,2, \cdots, n) \\
D_{i}^{-}=\sqrt{\sum_{j=1}^{n}\left(r_{i j}-H_{j}^{-}\right)^{2}},(j=1,2, \cdots, n)
\end{gathered}
$$

The relative closeness of each indicator $C_{i}$ is calculated, and each evaluation object is ranked according to the relative closeness. The higher the relative closeness, the better the evaluation object is, the higher the ranking, and the better the green development of urban logistics industry is

$$
C_{i}=\frac{D_{i}^{-}}{D_{i}^{+}+D_{i}^{-}}, C_{i} \in[0,1]
$$

\section{Evaluation Indicator System Construction}

\subsection{Evaluation Indicator Selection Principles}

The evaluation indicator system is an organic whole, and its construction influences the selection of evaluation indicators, which in turn affects the performance evaluation results. Combined with the industry norms and relevant policy documents of logistics industry, considering that most enterprises lack scientific and systematic evaluation standards, the common indicators unilaterally emphasize typicality, quantifiability and easy comprehensibility. Based on the development characteristics of the logistics industry in East China, this paper aims to ensure the authenticity and accuracy of the green development indicators of the logistics industry and construct an evaluation system applied to the green development of the logistics industry in East China. The following principles are mainly followed.

(1) Principle of comprehensiveness and systematization

The construction of the evaluation indicator system should reflect the actual situation of green development of logistics industry as comprehensively and systematically as possible, and closely link the logistics operation with all aspects of social development, and consider the design of the indicators as a complete systematic project.

(2) Principle of quantitative and qualitative integration

Quantitative and qualitative methods are two different research methods that people use based on objective things and implementation results. Quantitative analysis has the characteristics of quantification, precision, objectivity and complexity, while qualitative analysis has the characteristics of fuzzification, subjectivity and simplicity. The two have a complementary and dialectical relationship. In order to prevent the bias of indicator selection and ensure the accuracy and objectivity of evaluation results, the principle of combining quantitative and qualitative should be adopted.

(3) Principle of combining scientificity and professionalism

The evaluation of the green development of logistics industry should focus on both the overall scientific standardization and the local professionalism. The scientific nature refers to taking science as the guide, following the objective laws, taking certain facts as the basis, clarifying the basic concepts of each evaluation index, and using the scientific and standardized calculation methods. Professionalism means that the professional attributes of the operation and development of the logistics industry should be taken into account, and performance indicators should be established in accordance with industry norms and professional technical standards.

(4) Principle of practicability 
Practicality is an important principle that must be incorporated into the evaluation indicator system of this project. Further, practicality can be extended to include usability, cost-effectiveness, flexibility, operability, measurability and achievability. The concrete implementation of this principle should, firstly, it should be clear that in terms of green development performance evaluation of logistics industry in East China, the selection of indicators should be based on the conceptual nature, and the acquisition of parameters and related data should be simple. Secondly, the cost of each aspect should be considered in conjunction with the cost-benefit principle to ensure that the evaluation is feasible. In addition, the compatibility of indicator selection with statistical information and financial statements should also be considered, with appropriate number of indicators and consideration of the future development needs of the logistics industry in East China from a long-term perspective.

\subsection{Determination of the Indicator System}

According to China's Green Logistics Indicators and Accounting Method, the current situation of the development of green logistics industry and related literature, finance, resource, operation and environment are selected as the secondary indicators of the green development performance of logistics industry in East China. By consulting the statistical yearbook and other relevant reference materials, the tertiary indicators under the secondary indicators are selected in conjunction with the research theme, and the design principles of the evaluation indicator system are fully followed to evaluate the green development performance of logistics industry in East China from multiple perspectives and with multiple indicators. The details are shown in Table 1. As can be seen from Table 1 , there are three levels in the evaluation indicator system, 1 primary indicator, 4 secondary indicators and 8 tertiary indicators.

Table 1. The Evaluation Indicator System of Green Development Performance of Logistics Industry in East China

\begin{tabular}{|c|c|c|}
\hline Primary indicator & Secondary indicator & Tertiary indicator \\
\hline \multirow{8}{*}{$\begin{array}{c}\text { Green } \\
\text { development } \\
\text { performance of } \\
\text { logistics industry } \\
\text { (A) }\end{array}$} & \multirow{2}{*}{ Financial indicator (A1) } & $\begin{array}{l}\text { The total investment in fixed assets of transportation, storage } \\
\text { and postal industry (100 million yuan) (A11) }\end{array}$ \\
\hline & & $\begin{array}{l}\text { The added value of transportation, storage and postal industry } \\
\qquad(100 \text { million yuan) (A12) }\end{array}$ \\
\hline & \multirow{2}{*}{ Resource indicator (A2) } & $\begin{array}{l}\text { The number of employees in urban units of transportation, } \\
\text { storage and postal industry (ten thousand people) (A21) }\end{array}$ \\
\hline & & The ownership of road operating vehicles (unit) (A22) \\
\hline & \multirow{2}{*}{ Operational indicator (A3) } & The freight volume (ten thousand tons) (A31) \\
\hline & & The freight turnover (100 million yuan / kilometers) (A32) \\
\hline & \multirow{2}{*}{ Environmental indicator (A4) } & $\begin{array}{l}\text { The electricity terminal consumption of transportation, } \\
\text { storage and postal industry (100 million kilowatt-hour) (A41) }\end{array}$ \\
\hline & & $\begin{array}{l}\text { The diesel terminal consumption of transportation, storage } \\
\text { and postal industry (ten thousand tons) (A42) }\end{array}$ \\
\hline
\end{tabular}

Among the tertiary indicators, the total investment in fixed assets of transportation, storage and postal industry refers to the workload and related costs of fixed assets built and purchased for transportation, storage and postal industry in the reporting period. The added value of transportation, storage and postal industry refers to the monetary performance of the final results provided by transportation, storage and postal industry for the society in a certain period of time. The number of employees in urban units of transportation, storage and postal industry reflects the human resource situation. The ownership of road operating vehicles reflects the equipment resource situation. The freight volume indicates the amount of goods completed or to be completed for transportation in 
goods transport. The freight turnover integrally reflects the needs of all sectors of the national economy for goods transport in a certain period and the total amount of goods transport work provided by the transport sector for the society. The electricity terminal consumption of transportation, storage and postal industry reflects the consumption of electrical energy. The diesel terminal consumption of transportation, storage and postal industry reflects the consumption of chemical and thermal energy. In summary, a complete and systematic, scientific and professional evaluation system has been established.

\section{Empirical Analysis}

\subsection{Data Source and Processing}

The provinces and cities included in East China are Jiangsu Province, Zhejiang Province, Anhui Province, Shandong Province, Jiangxi Province, Fujian Province and Shanghai City. Therefore, on the basis of the green development evaluation indicator system of the logistics industry in East China established in this study, the original data information of the green development evaluation indicators of the logistics industry in East China was collected by consulting a large number of statistical yearbooks and related materials. The data selected for this study are mainly from the China Statistical Yearbook (2015-2019), China Logistics Statistical Yearbook, China Tertiary Industry Statistical Yearbook (2015-2019), China Transportation Statistical Yearbook (2015-2019) and China Energy Statistical Yearbook (2015-2019), as well as the provincial and municipal statistical bureau networks for 2015-2019 Statistical Bulletin of National Social and Economic Development.

Some of the required indicator data need to be calculated specifically. For example, the data of the number of road operating vehicles cannot be obtained directly from the Yearbook, but the number of road operating goods vehicles and the number of road operating passenger vehicles can be obtained directly, so the number of the two can be added together to obtain the total number of road operating vehicles. The data of other indicators can be obtained directly from the yearbook. The detailed data of indicators are shown in the appendix.

\subsection{Evaluation of Green Development of Logistics Industry in East China}

\subsubsection{Evaluation of Single Indicator of Green Development of Logistics Industry in East China}

According to the definition and connotation of entropy weighting TOPSIS model, the raw data related to the development of logistics industry in East China from 2015-2019 were taken as the focus of the study, to evaluate the green development level of logistics industry of the sample. We first analyzed the status of four indicators of financial indicators, resource indicators, operational indicators and environmental indicators of six provinces and one city in East China separately.

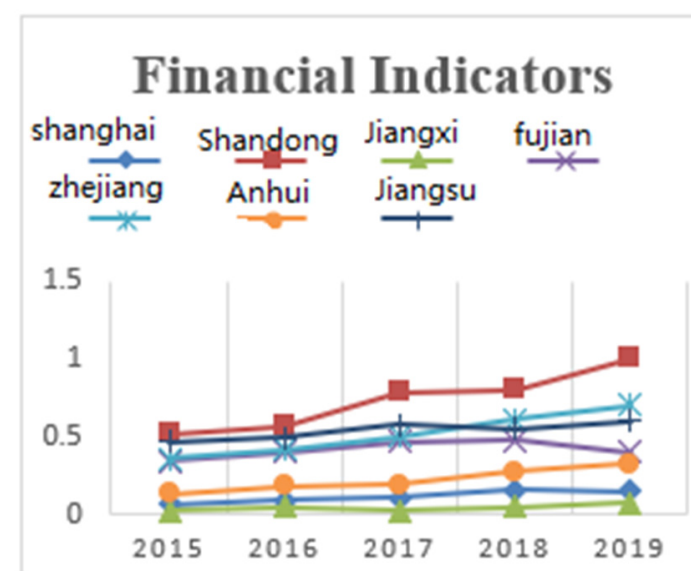

Figure 1. Financial Performance of Green Development of Logistics Industry of provinces and cities in East China in 2015-2019 
The performance status of each individual indicator of green development of logistics industry in each province and city in East China from 2015 to 2019 was calculated according to the formula (1) to (11), and its specific relative closeness (score) and ranking are shown in Table 2 and Figure 1, Figure 2, Figure 3 and Figure 4 below.

Table 2. Results of Calculated Indicator Weight through Entropy Method

\begin{tabular}{|c|c|c|c|c|c|}
\hline \multicolumn{6}{|c|}{ Results of Calculated Indicator Weight through Entropy Method } \\
\hline $\begin{array}{l}\text { Secondary } \\
\text { indicator }\end{array}$ & $\begin{array}{l}\text { Weighting } \\
\text { coefficient }\end{array}$ & Tertiary indicator & $\begin{array}{l}\text { Information } \\
\text { entropy } \\
\text { value } e\end{array}$ & $\begin{array}{l}\text { Information } \\
\text { avail value } d\end{array}$ & $\begin{array}{c}\text { Weighting } \\
\text { coefficient } \\
w \\
\end{array}$ \\
\hline \multirow{2}{*}{$\begin{array}{l}\text { Financial } \\
\text { indicator }\end{array}$} & \multirow{2}{*}{$24.64 \%$} & $\begin{array}{c}\text { The total investment in fixed assets of } \\
\text { transportation, storage and postal } \\
\text { industry (100 million yuan) }\end{array}$ & 0.9644 & 0.0356 & $13.81 \%$ \\
\hline & & $\begin{array}{c}\text { The added value of transportation, } \\
\text { storage and postal industry (100 } \\
\text { million yuan) }\end{array}$ & 0.9721 & 0.0279 & $10.83 \%$ \\
\hline \multirow{2}{*}{$\begin{array}{l}\text { Resource } \\
\text { indicator }\end{array}$} & \multirow[t]{2}{*}{$26.32 \%$} & $\begin{array}{l}\text { The number of employees in urban } \\
\text { units of transportation, storage and } \\
\text { postal industry (ten thousand people) }\end{array}$ & 0.9818 & 0.0182 & $7.07 \%$ \\
\hline & & $\begin{array}{l}\text { The ownership of road operating } \\
\text { vehicles (unit) }\end{array}$ & 0.9504 & 0.0496 & $19.25 \%$ \\
\hline \multirow{2}{*}{$\begin{array}{l}\text { Operational } \\
\text { indicator }\end{array}$} & \multirow{2}{*}{$26.21 \%$} & $\begin{array}{l}\text { The freight volume (ten thousand } \\
\text { tons) }\end{array}$ & 0.973 & 0.027 & $10.46 \%$ \\
\hline & & $\begin{array}{l}\text { The freight turnover (100 million } \\
\text { yuan / kilometers) }\end{array}$ & 0.9594 & 0.0406 & $15.75 \%$ \\
\hline \multirow{2}{*}{$\begin{array}{l}\text { Environmental } \\
\text { indicator }\end{array}$} & \multirow{2}{*}{$22.82 \%$} & $\begin{array}{l}\text { The electricity terminal consumption } \\
\text { of transportation, storage and postal } \\
\text { industry ( } 100 \text { million kilowatt-hour) }\end{array}$ & 0.9731 & 0.0269 & $10.44 \%$ \\
\hline & & $\begin{array}{l}\text { The diesel terminal consumption of } \\
\text { transportation, storage and postal } \\
\text { industry (ten thousand tons) }\end{array}$ & 0.9681 & 0.0319 & $12.38 \%$ \\
\hline
\end{tabular}

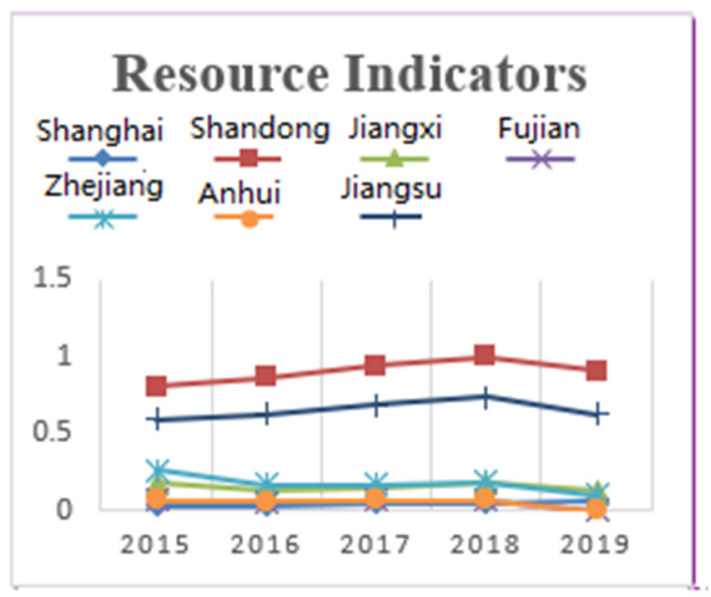

Figure 2. Resource Performance of Green Development of Logistics Industry of provinces and cities in East China in 2015-2019

As shown in Table 2, according to weighting coefficients the tertiary indicators, there is not much difference in the importance of the tertiary indicators, among which the highest weight of $19.25 \%$ is given to the ownership of road operating vehicles in the resource indicator, the second, third and fourth are the turnover of goods in the operational indicator, the total investment in fixed assets in transportation, storage and postal industry in the financial indicator, and the terminal diesel consumption in transportation, storage and postal industry in the environmental indicator. That is, the first four tertiary indicators are taken from one of the four secondary indicators respectively. The 
Volume 17 (2022)

weights of the four secondary indicators are $24.64 \%, 26.32 \%, 26.21 \%$ and $22.82 \%$, which are relatively balanced, indicating that the indicators are reasonably selected.

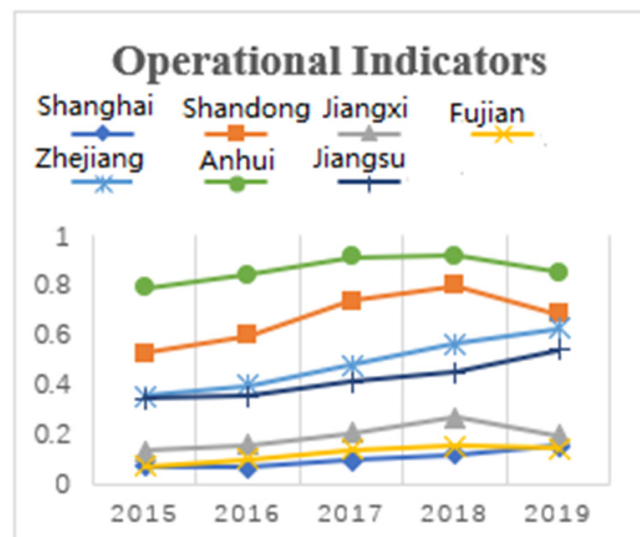

Figure 3. Operational Performance of Green Development of Logistics Industry of provinces and cities in East China in 2015-2019

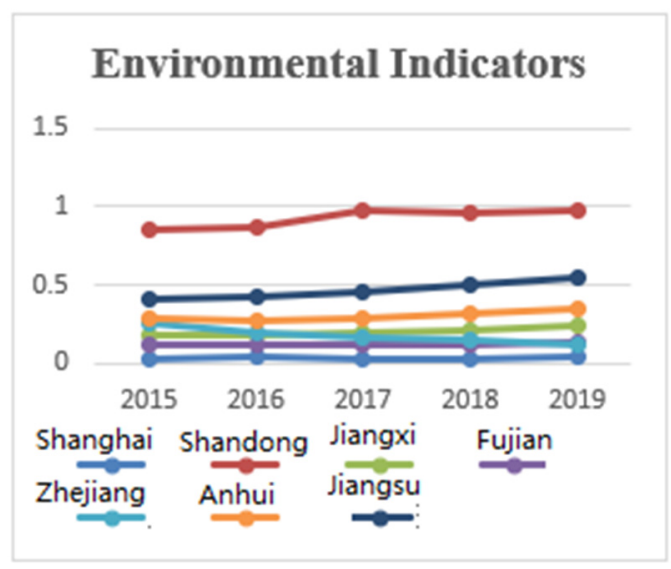

Figure 4. Environmental Performance of Green Development of Logistics Industry of provinces and cities in East China in 2015-2019

From Figure 1, it can be seen that the economic development of logistics industry in East China held a stable growth trend in general from 2015 to 2019, among which Shandong Province leads other provinces and cities with an absolute advantage, and its rise is the largest, followed by Zhejiang Province, Jiangsu Province, Fujian Province, Anhui Province, Shanghai City, and Jiangxi Province. In addition, in the resource indicators and environmental indicators, Shandong Province is also far ahead in the development of the entire East China region, only in second place in the operational indicators, with Anhui Province ranking the first. The reason why Shandong Province can achieve such results is closely related to its unique geographical location advantage. Shandong Province is located in the Bohai Sea Economic Zone and along the Yellow River Economic Zone intersection, from south to north respectively in Jiangsu, Anhui, Henan, Hebei four provinces bordering, is the intersection of East China and North China, the unique geographical location, making Shandong in the acquisition of resources and economic development more advantageous. In addition, in recent years, Shandong has also developed rapidly in the logistics industry, making full use of its own advantages to continuously promote industrial transformation and upgrading, closely following the national and local policies to carry out a series of reform programs to continuously reduce logistics costs and promote supply chain applications and innovation. At the same time, this also highlights the advantages of Shandong as a large province in terms of population and area, with a large economic volume and abundant social resources, of which $60 \%$ of the cities are third-tier cities and above, such 
as Jinan, which is one of the largest state-owned highway passenger stations in China, or an international-level bus terminal, and Weifang, which is the intersection of two national development axes, the Jin-Shanghai corridor development axis and the Tai Shi-Jiqing development axis, and is a national Weifang is the intersection of two national development axes, namely, the Jin-Shanghai corridor development axis and the Tai Shi-Jiqing development axis, and is an important node of the national "four vertical and four horizontal" fast railroad network.

Jiangsu Province follows Shandong Province, as seen in Figure 2 and Figure 4, ranking second in terms of resource and environmental indicators and fourth in terms of operational indicators. This is due to Jiangsu Province's in-depth practice and implementation of the "13th Five-Year Plan" logistics industry development plan, the in-depth implementation of the "Belt and Road", the Yangtze River Economic Belt and other national strategies, promote industrial restructuring, promote supply-side structural reform, change the mode of economic development, logistics The main body gradually grows, the scale of efficiency is steadily improved, on the whole, although the logistics industry in Jiangsu Province has entered a new stage of transformation and upgrading, but there are still some problems, such as logistics costs are still high, the industry's profitability has declined, which is reflected in the financial indicators of Jiangsu Province's competitive advantage is not very prominent. The green development of logistics industry in Anhui Province is in the middle and lower level in the whole activity area, but it can be seen from Figure 3 that Anhui Province is in the first advantage in the operational indicator, which is due to the vigorous development of Anhui Province in infrastructure, park construction, transportation network construction, etc. By promoting the construction progress of major projects, making efforts to introduce high-end talents and advanced technology, improving infrastructure and service level, turning the hub by pushing forward the construction progress of major projects, introducing high-end talents and advanced technology, improving infrastructure and service level, and turning the host city into a hub economic node with high traffic, high gathering and high consumption. At the same time, Anhui Province is steadily advancing in other indicators by virtue of its advantageous geographical location close to the Yangtze River Delta economic zone centered on Shanghai and the influence of economic radiation from developed cities in Jiangsu, Zhejiang and Shanghai.

\subsubsection{Comprehensive Performance Evaluation of Green Development of Logistics Industry in East China}

Based on the entropy weighting TOPSIS method, the comprehensive performance evaluation of the green development of logistics industry in East China is shown in Table 3 and Figure 5.

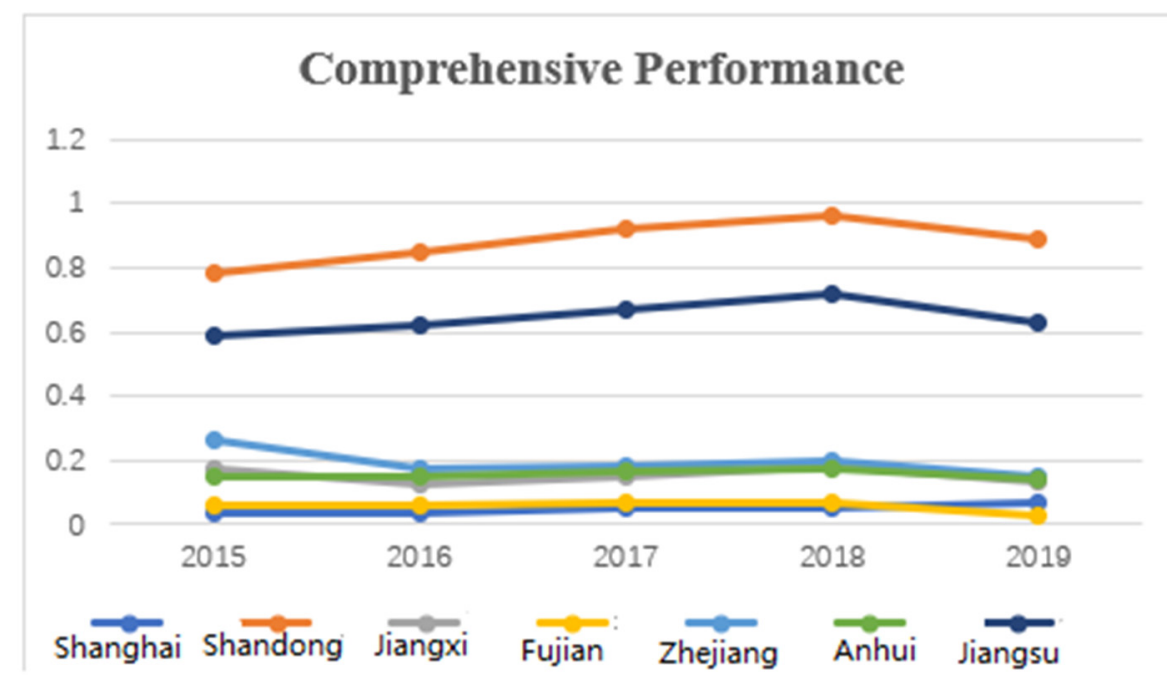

Figure 5. Comprehensive Performance of Green Development of Logistics Industry of provinces and cities in East China in 2015-2019 
Based on the entropy weighting TOPSIS method, the regional green logistics performance ranking was obtained by analyzing the data related to the development of logistics industry in six provinces and one city in East China, as shown in Table 3. The green development of logistics industry in six provinces and one city for five consecutive years (2015-2019) formed 35 evaluation objects, and from Table 3, the positive and negative ideal solution distance and relative closeness of each evaluation can be obtained, as well as the resulting ranking. From the data in the table, it can be seen that the relative closeness of each province and city for five consecutive years does not differ much, and most of them show a continuous growth trend, which indicates that the green development of logistics industry in each province and city is relatively stable and shows an overall upward growth trend.

Table 3. TOPSIS Evaluation Calculation Results

\begin{tabular}{|c|c|c|c|c|}
\hline \multicolumn{5}{|c|}{ TOPSIS Evaluation Calculation Results } \\
\hline Item & $\begin{array}{l}\text { Distance to the positive } \\
\text { ideal solution } D_{i}^{+}\end{array}$ & $\begin{array}{l}\text { Distance to the negative } \\
\text { ideal solution } D_{i}^{-}\end{array}$ & Relative closeness $C_{i}$ & Ranking \\
\hline 2015 Shanghai & 180309.930 & 6139.237 & 0.033 & 33 \\
\hline 2016 Shanghai & 180384.547 & 6098.934 & 0.033 & 34 \\
\hline 2017 Shanghai & 177039.543 & 9470.174 & 0.051 & 32 \\
\hline 2018 Shanghai & 176171.608 & 10441.260 & 0.056 & 31 \\
\hline 2019 Shanghai & 173995.756 & 12662.282 & 0.068 & 27 \\
\hline 2015 Shandong & 39952.111 & 147285.347 & 0.787 & 5 \\
\hline 2016 Shandong & 29116.788 & 158373.789 & 0.845 & 4 \\
\hline 2017 Shandong & 14644.305 & 173082.465 & 0.922 & 2 \\
\hline 2018 Shandong & 6792.145 & 184889.145 & 0.965 & 1 \\
\hline 2019 Shandong & 20258.979 & 167239.458 & 0.892 & 3 \\
\hline 2015 Jiangxi & 152872.107 & 33096.934 & 0.178 & 15 \\
\hline 2016 Jiangxi & 162358.911 & 23586.021 & 0.127 & 25 \\
\hline 2017 Jiangxi & 158881.938 & 27134.109 & 0.146 & 21 \\
\hline 2018 Jiangxi & 152299.439 & 33786.395 & 0.182 & 14 \\
\hline 2019 Jiangxi & 161638.109 & 24400.632 & 0.131 & 24 \\
\hline 2015 Fujian & 174234.654 & 11684.888 & 0.063 & 29 \\
\hline 2016 Fujian & 174507.624 & 11491.536 & 0.062 & 30 \\
\hline 2017 Fujian & 173923.398 & 12267.480 & 0.066 & 28 \\
\hline 2018 Fujian & 173346.448 & 12924.397 & 0.069 & 26 \\
\hline 2019 Fujian & 185095.245 & 4882.820 & 0.026 & 35 \\
\hline 2015 Zhejiang & 136481.070 & 49557.068 & 0.266 & 11 \\
\hline 2016 Zhejiang & 154068.661 & 32950.775 & 0.176 & 16 \\
\hline 2017 Zhejiang & 153381.795 & 34495.474 & 0.184 & 13 \\
\hline 2018 Zhejiang & 150513.943 & 38110.693 & 0.202 & 12 \\
\hline 2019 Zhejiang & 164458.807 & 28276.068 & 0.147 & 20 \\
\hline 2015 Anhui & 171568.757 & 29279.551 & 0.146 & 22 \\
\hline 2016 Anhui & 171957.517 & 30938.895 & 0.152 & 19 \\
\hline 2017 Anhui & 171521.820 & 34891.145 & 0.169 & 18 \\
\hline 2018 Anhui & 171020.361 & 35387.748 & 0.171 & 17 \\
\hline 2019 Anhui & 182927.851 & 29305.522 & 0.138 & 23 \\
\hline 2015 Jiangsu & 77395.620 & 109275.351 & 0.585 & 10 \\
\hline 2016 Jiangsu & 71265.823 & 115593.282 & 0.619 & 9 \\
\hline 2017 Jiangsu & 61099.509 & 125809.837 & 0.673 & 7 \\
\hline 2018 Jiangsu & 52144.466 & 134950.067 & 0.721 & 6 \\
\hline 2019 Jiangsu & 69548.489 & 116478.598 & 0.626 & 8 \\
\hline
\end{tabular}


According to this ranking, the information conveyed more intuitively is drawn to get the comprehensive performance of the green development of logistics industry in each province and city in East China from 2015 to 2019 as shown in Figure 5. The results shown in Figure 5 indicate that Shandong Province ranked the highest and has the best green development of logistics industry, far exceeding the development of other provinces and cities, which was mainly due to the "13th FiveYear Plan" development plan and other opportunities to establish a series of development indicators, and focus on building a universal and equal, efficient and convenient, intelligent, safe and reliable, green and low-carbon logistics comprehensive development system. Jiangsu Province and Zhejiang Province took the second and third places respectively, and Fujian Province and Shanghai took the last two places. In addition, from 2015 to 2018, it can be seen that the green development of the logistics industry in all provinces and cities in East China showed a steady upward trend, with Shandong Province and Jiangsu Province rising more rapidly and other provinces and cities rising more slowly. From 2018 to 2019, except for Shanghai, which still held a slow growth trend, the green development of the logistics industry in all other provinces presented a small downward trend compared with the previous year. On the whole, Shandong and Jiangsu provinces were more outstanding in the green development of the logistics industry, while Zhejiang, Anhui and Jiangxi provinces were on a par with each other in terms of the level of green development of the logistics industry, which is a bit behind Shandong and Jiangsu provinces. The logistics industry green development levels of Fujian Province and Shanghai were the lowest, and there was still a lot of room for upward mobility in the future.

\section{Conclusion}

Based on the background of the "Carbon Peak and Carbon Neutrality" Goal, combined with the industry norms and relevant policy documents of logistics industry, this study selected secondary indicators containing four aspects of finance, resource, operation and environment, and eight tertiary indicators, and constructed the evaluation indicator system of green development of logistics industry in East China. Based on this, quantitative analysis and qualitative analysis of the green development of logistics industry in six provinces and one city in East China were conducted using entropy weighting TOPSIS method. Conclusions are obtained: First, the overall level of green development of logistics industry in East China from 2015 to 2019 is good, which is related to the growth of demand for logistics industry development, the improvement of green carbon reduction awareness, and the enhancement of construction investment, industry operation and economic capacity. At the same time, the development of each province and city is relatively stable with little difference, which is conducive to the synchronized and coordinated green development of the logistics industry in East China region as a whole, and can actively drive the logistics development of central and western cities and other neighboring cities. Second, according to the comprehensive evaluation ranking results, the six provinces and one city in East China ranked in order of green development of logistics industry are Shandong, Jiangsu, Zhejiang, Anhui, Jiangxi, Fujian and Shanghai. Among them, Shandong Province leads the development, Jiangsu has an obvious upward trend, Zhejiang, Anhui and Fujian have a stable but slow development, and Fujian and Shanghai have a low level of green development of logistics industry, which need to be further improved. At the same time, we can also see the strong influence of economic radiation effect, which is well reflected in the development of Anhui Province, which ranks first among the six provinces and one city in terms of resource index development, thanks to the influence of the high-speed development of the neighboring economically developed provinces of Jiangsu, Zhejiang and Shandong on the one hand, and the importance of green development of logistics industry in Anhui Province on the other hand, through its own industrial structure adjustment and resource investment to enhance logistics High-quality development. Thirdly, in order to further promote the green development of logistics industry in East China, it is suggested that the six provinces and one city should strengthen regional cooperation, establish inter-provincial logistics cooperation management system, realize the sharing of materials, information, technology and talents, 
etc., and lead if with strong, strong cooperation. Each province and city should base on the actual development status of local logistics industry, firmly grasp the green needs of logistics industry development, establish a scientific and reasonable operation system, increase the investment and reasonable use of logistics resources, continuously reduce logistics costs, re-create the supply chain, value chain and industrial chain, and fully promote the innovation-driven, green and cooperative development of logistics industry.

\section{References}

[1] Li G, Lyu S. Research on the Optimization of Industrial Structure in Beijing-Tianjin-Hebei under the Perspective of "Carbon Peak and Carbon Neutrality" Goal [J/OL]. Journal of Hebei University of Economics and Business, 1-9 [2022-01-29]. DOI: 10.14178/j.cnki.issn1007-2101.20220105.006. (In Chinese).

[2] Chen M, Shang M, Shi L, et al. Competitiveness Evaluation of Regional Logistics Industry from the Perspective of High-Quality Development [J]. Trade Fair Economy, 2021(22): 85-87. (In Chinese).

[3] Li Z, Zhang F. An Empirical Study on the Efficiency of Logistics Industry in East China Region [J]. Business News, 2018(10):102+104. (In Chinese).

[4] Mei G, Gong Y, Wan J, et al. Study of the Efficiency Measurement of Logistics Industry in East China Based on Three-stage DEA Model [J]. Management Review, 2019, 31(10):234-241. DOI: 10. 141 20/j. cnki.cn11-5057/f.2019.10.021. (In Chinese).

[5] Wang Y. Study on the Evaluation of Regional Logistics Capacity Based on Factor Analysis Method: Taking Hebei Province as an Example [J]. Journal of Tonghua Normal University, 2021, 42(09):96-100. DOI: 10.13877/j.cnki.cn22-1284.2021.09.015. (In Chinese).

[6] Wang L, Wang B. Study on Carbon Emission Characteristics of Logistics Enterprises in Henan Province under Background of Energy Saving and Emission Reduction[J]. Resource Development \& Market, 2015, 31 (04):452-454. (In Chinese).

[7] Yang S, Zhang Y. Research on Green Transformation of Logistics Industry Based on Energy Efficiency[J]. Journal of North China Electric Power University (Social Sciences), 2021(04):40-52. DOI: 10. 14092/ j. cnki.cn11-3956/c.2021.04.005. (In Chinese).

[8] Xie A, Xue Q, Zhou Z. Research on Performance Evaluation and Influencing Factors of Regional Green Logistics: Based on the Data of "Six Provinces and One City in East China" [J]. Journal of Jiujiang University (Natural Science Edition),2019,34(02):44-50. DOI: 10.19717/j.cnki.jjun.2019.02.013. (In Chinese).

[9] Su C, Chen C. Research on ESG Evaluation System of Listed Companies Under the New Development Concept: An Example of Listed Companies in Heavy Pollution Manufacturing Industry [J/OL]. Finance and Accounting Monthly,1-6[2022-01-29]. https:// kns. cnki. net/ kcms/ detail/ 42.1290. F.2021 1229. 11 01. 008.html. (In Chinese).

[10] Zhou Y. An Empirical Study on the Relationship between the Development of Logistics Industry and Regional Economic Growth in East China [D]. Shandong University of Finance and Economics, 2016. (In Chinese).

[11] Soleimani H, Mohammadi M, Fadaki M, et al. Carbon-efficient closed-loop supply chain network: an integrated modeling approach under uncertainty[J]. Environmental Science and Pollution Research, 2021 (8).

[12] Choudhary S, Kumar A, Luthra S, et al. The adoption of environmentally sustainable supply chain management: Measuring the relative effectiveness of hard dimensions [J]. Business Strategy and the Environment, 2020.

[13] Ramanathan U, Mazzola E, Mohan U, et al. How selection of collaborating partners impact on the green performance of global businesses? An empirical study of green sustainability [J]. Production Planning and Control, 2020(3):1-16.

[14] Rehman S A, Sharif A, Hêri Golpra, et al. A Green Ideology in Asian Emerging Economies: From Environmental Policy and Sustainable Development[J]. Sustainable Development, 2019, 27(2). 
[15] Hooker R E, Seman N, Govindan K, et al. The mediating effect of green innovation on the relationship between green supply chain management and environmental performance[J]. Journal of Cleaner Production, 2020, 229.

[16] Khan S, Jian C, Zhang Y, et al. Environmental, Social and Economic Growth Indicators Spur Logistics Performance: From the Perspective of South Asian Association for Regional Cooperation Countries[J]. Journal of Cleaner Production, 2019, 214(MAR.20):1011-1023.

[17] Laari S, Tyli J, Ojala L. The effect of a competitive strategy and green supply chain management on the financial and environmental performance of logistics service providers[J]. Business Strategy and the Environment, 2018, 27(7):872-883.

[18] Sb A, Pdb C, Djb D, et al. Effect of eco-innovation on green supply chain management, circular economy capability, and performance of small and medium enterprises. 2022.

[19] Rs A, Il B, Sg C, et al. green supply chain management practices and third-party logistics providers' performances: A fuzzy-set approach - ScienceDirect[J]. International Journal of Production Economics, 2021.

[20] Agyabeng-Mensah Y, Liang T. The relationship among green human capital, green logistics practices, green competitiveness, social performance and financial performance [J]. Journal of Manufacturing Technology Management, 2021, ahead-of-print(ahead-of-print). 